\title{
UNDERSTANDING OF NAVIGATIONAL INFORMATION SYSTEMS
}

\begin{abstract}
Navigational information systems became one of the main devices on ship's bridge supporting navigators in evaluation of navigational situation and undertaking decisions. For instance ECIDS supports navigation by gathering information and automating some process like plotting of position of own ship and other objects on the scene. Any navigational information system has got advantages and limitations. Their understanding should help navigators to perform watches in a safer way. This article presents a discussion on some deficiencies of navigational information systems. Discussion is underlined by three accidents, which show when misunderstanding or overreliance may lead to catastrophic consequences.
\end{abstract}

\section{Keywords:}

ECDIS, e-navigation, information systems.

\section{INTRODUCTION}

In recent years we could observe revolutionary development of marine equipment associated with modern navigation systems as well as the broad systems of engine control and supervision of cargo handling operations. In particular, passenger ships, container ships and tankers are gradually becoming more automated. Large systems and information technology are increasingly being used on the bridges.

This process has encountered two problems. The first is inadequate, outdated curriculums of ship's personnel training; the second is connected with handling of such systems and is recognized in the reports the IMO Maritime Safety Committee [10] — 'human factor'. The operators often do not understand all the characteristics and limitations of the systems. Given the increasing prevalence of automated systems, which become very important for the proper functioning of the ship, it is important to reduce their handling difficulties. They have been already included in the design, development and implementation of systems. 
The development of automation can be very beneficial for maritime industry. It can help to relief crews and human resources to perform other duties. However, it can have also negative aspect by increasing the risk of operator error and lead to an incident or accident. Rule no 5 - lookout says Every vessel shall at any time maintain proper lookout by sight and hearing as well as by all available means appropriate (...). It means navigator should monitor the navigational situation instead of ship's automated system itself.

\section{FACING THE NEGATIVE EFFECTS OF AUTOMATION}

Problems described have been noticed by International Maritime Organization and the actions were taken to counteract the negative effects of automation. In 2000, 'Guidelines on ergonomic criteria for bridge equipment and layout' [7] were introduced, in 2003, 'Guidance for the operational use of integrated bridge system (IBS)' [8] and 'Issues to be considered when introducing new technology on board ship' [9] respectively.

The analysis of accidents and incidents at sea and in ports were performed. The results were presented at meetings of the IMO sub-committees. As a result of researches, in 2006, a set of recommendations were proposed. They should be implemented in order to reduce the negative impact of automation on safety of navigation [10].

The recommendations were directed to:

- shore-based company managers;

— shipboard management;

— seafarers using automated systems;

— training providers.

Specific issues were identified related to the errors of operators of automated systems in use, as follow:

- over-reliance on automation of the crews, which leads to a false sense of security, that the automation will always handle the situation safely;

- confidence in the data presented by the automated control systems and this leads to a lack of additional manual supervision;

- lack of understanding of automated control systems and any inherent weaknesses they may have; 
- improper ergonomic design that can have a detrimental impact on the performance and increase the incidence of errors;

- data displayed on the screen of automatic control systems, human-computer interfaces, can be very confusing for the user;

- control systems designed to run automatically are not sufficiently obvious, error information is not clear;

- the consequences that may arise if a ship crews are aware that the control system will automatically operate in case of operator error;

- errors in the maintenance and calibration, development of automatic control systems can lead to catastrophic consequences;

- overload the crew with information;

- lack of standardization by different manufacturers impossible to understand all the characteristics of individual systems.

\section{OVER-RELIANCE OF INFORMATION SYSTEMS}

In recent time, number of accidents occurs in shipping which have been caused mainly by improper use or misunderstanding of onboard information systems.

Generally in every accident a number of factors (errors) were involved leading to instability of whole system. Let us focus just on information systems like Electronic Chart Display and Information System (ECDIS), Electronic Navigational Chart (ENC), Vessel Monitoring System (VMS), Automatic Radar Plotting Aid (ARPA), Automatic Identification System (AIS).

With advances in technology and implemented the provisions of the SOLAS Convention, the primary information tool for navigation is an integrated system ECDIS.

Regulations of mandatory carriage of Electronic Chart Display and Information Systems (ECDIS), under SOLAS convention (chapter V Safety of Navigation), were agreed to by the Sub-Committee on Safety of Navigation (NAV) at its $54^{\text {th }}$ session. Ships engaged on international voyages shall be fitted with an Electronic Chart Display and Information System according to detailed schedule which starts in 2012 (NAV, 2008).

Mandatory carriage of ECDIS will not ensure expected level of safety of navigation. There are many issues still to be solved like the variety of different ECDIS software products and their possible configuration and data-simulation opportunities within an ECDIS training environment. Understanding of ECDIS and its limitation and difference with former aids is crucial. As shown on (fig. 1) number of ship's accidents in word fleet is continuously growing up despite the development of new technology. The very last example of grounding of very well equipped and automated $\mathrm{m} / \mathrm{v}$ 'Costa Concordia' just proves this fact. 


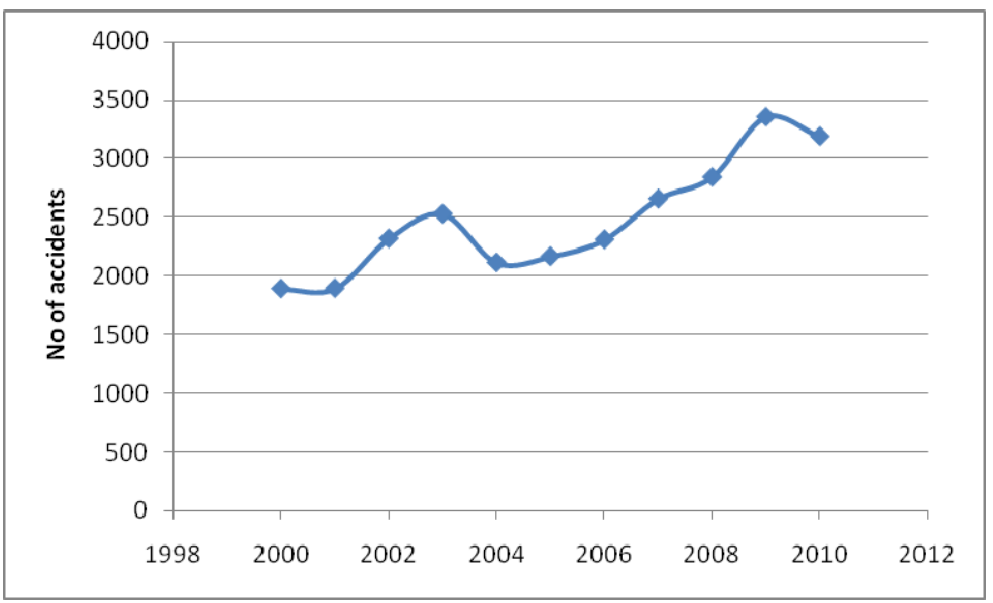

Fig. 1. Total number of navigational accidents of sea-going vessels [5]

Let us present few accidents which have happened recently and illustrate this problem.

\section{Case No. 1: grounding of $\mathrm{m} / \mathrm{v}$ 'Pride of Canterbury'}

On 31 January 2008, the Passenger ferry, 'Pride of Canterbury', grounded on a charted wreck while sheltering from heavy weather in an area known as 'The Downs' off Deal, Kent [6]. The vessel overshot the northern limit of the safe area before the turn was started. The officer of the watch (OOW) became aware that the vessel was passing close to a charted shoal, but he was unaware that there was a charted wreck on the shoal (fig. 2). The officer was navigating by eye and with reference to an electronic chart system but he was untrained in the use and limitations of the system.

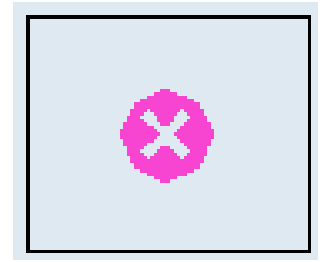

Fig. 2. Isolated danger of depth less than the safety contour: wrecks, obstructions, under water rocks [4]

The wreck would not have been displayed on the electronic chart due to the user settings in use at the time. 

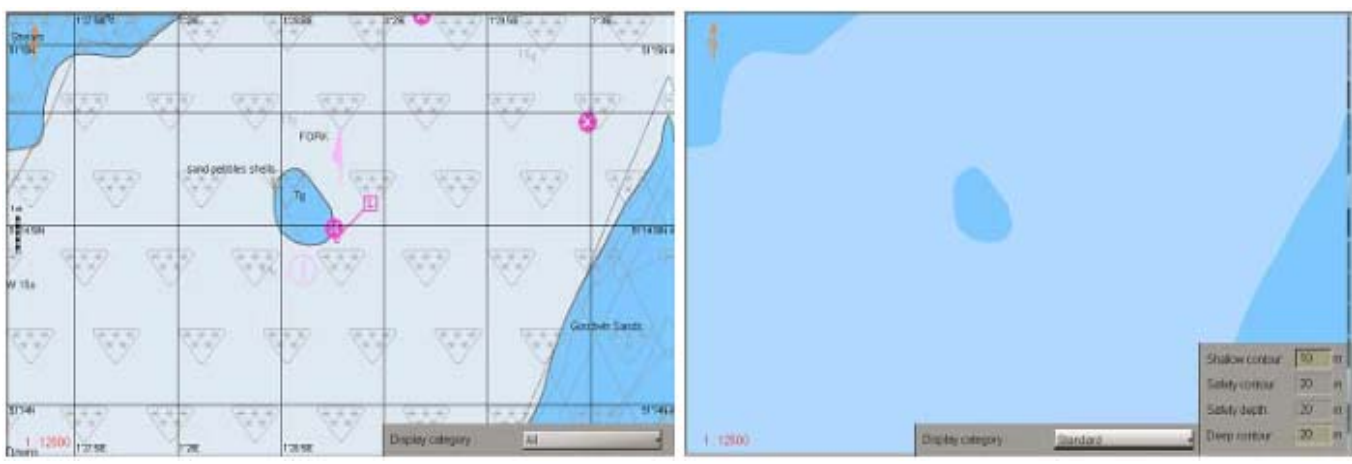

Fig. 3. Extract from ECDIS 3000-i showing alternative display settings for ENC charts for area in question: a) wreck visible; b) wreck not visible [own study]

In that case the lack of proper training in the use of ECDIS possibly led to the wreck being undetected. It is possible that the wreck on the shallow patch was displayed, but that the ECDIS symbol was misunderstood. Display options permit differences between the symbols displayed on paper charts and on ENC.

Another explanation, which is also linked to a lack of proper training, is that the 'misapplication' of certain user settings may resulting a dangerous underwater obstruction not being displayed on the screen (fig. 3). If the initial value for the safety contour is selected without understanding the constraints and the option for display of obstructions is set inappropriately. An ECDIS may not display the underwater hazards with sufficient clarity to alert the navigator. If a passage plan had been drawn using the Voyage Management System (VMS), and the VMS safety check function had been used, the presence of dangers on the route would have been automatically highlighted.

\section{Case No. 2: grounding of $\mathrm{m} / \mathrm{v}$ 'Cortesia'}

On 2 of January 2008 another ship, 6170 TEU container m/v 'Cortesia' ran aground on the Varne Bank in English Channel [3]. In good weather conditions the officer of the watch misjudged the navigational situation. He made non necessary evasion maneuver leading through shallow water just between cardinal buoys marking it (fig. 4). Due to inverse color allocation in night mode and activation of paper chart symbols, the boys and boundaries of shallow water were difficult to recognize (fig. 5). Following that circumstances OOW put ship in imminent danger, he misunderstood alarms issued by VMS. Finally being aground he was not aware about this fact. 


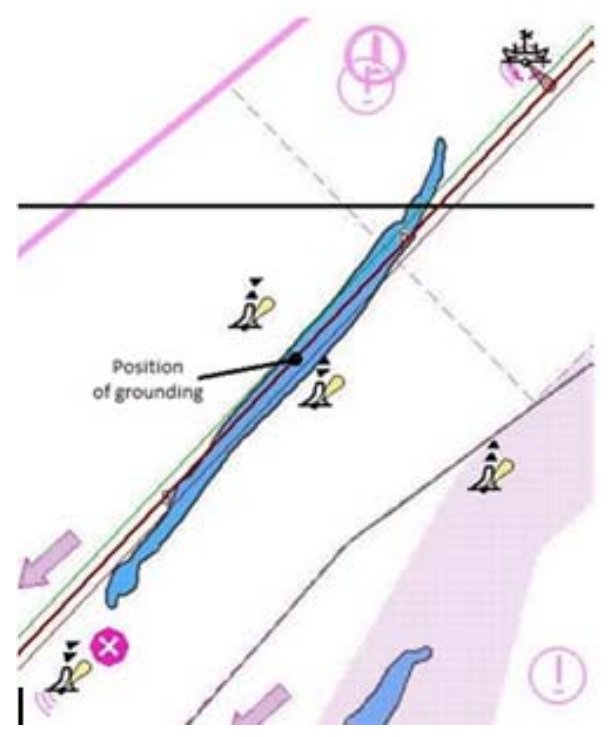

Fig. 4. Plotted evasion maneuver by $\mathrm{m} / \mathrm{v}$ 'Cortesia' through buoyed shallow water [own study]

Investigation showed that during a bridge watch, the OOW relied too much on the ECDIS displays. Furthermore even so, mistake could have been avoided if handling of the information system and the interpretation of the chart display would have been correct. If OOW had selected a better night display or had chosen a 2-color display in conjunction with a better setting of the safety contour he would have, even in the night, noticed the absolutely non-navigable critical depth he was approaching.
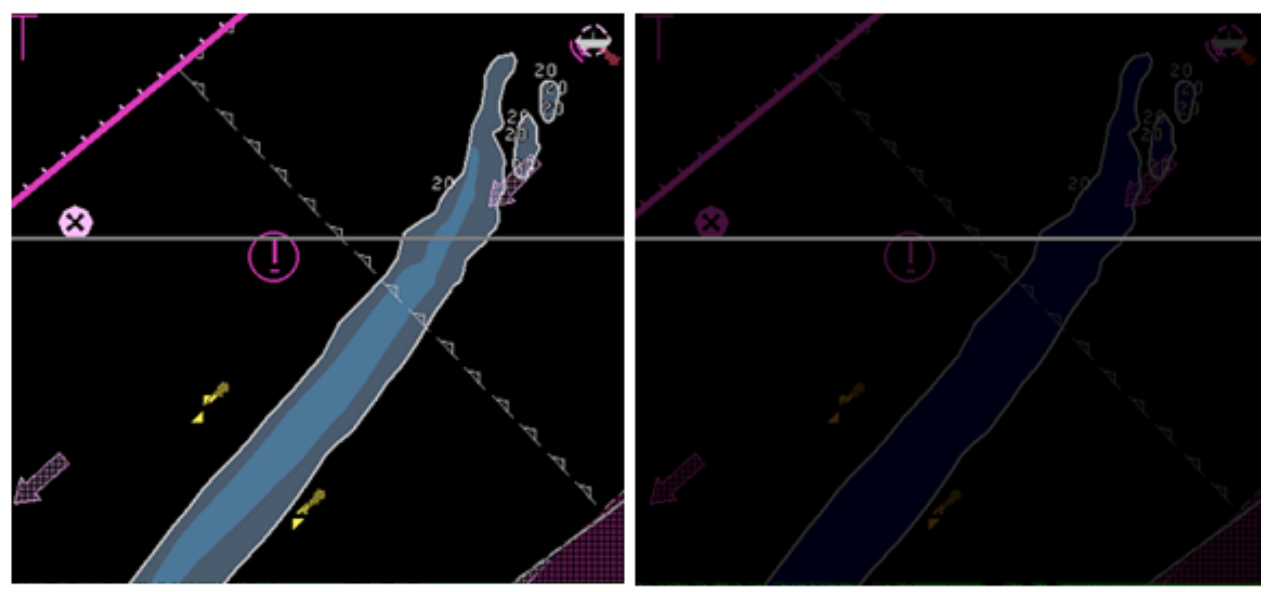

Fig. 5. Dusk and inverted dusk display of shallow water — Varne Bank by ECDIS [own study] 


\section{Case No. 3: collision between $\mathrm{m} / \mathrm{v}$ 'Gdynia' and m/v 'Fhu Shan Hai'}

Collision between $\mathrm{m} / \mathrm{v}$ 'Gdynia' and $\mathrm{m} / \mathrm{v}$ 'Fhu Shan Hai' happened in very good weather conditions near the northern edge of Bornholm Island at noon time [2]. The master of 'Gdynia' had observed a large vessel on the starboard side. He has not plotted the vessel on the radar but estimated that, it will pass clear of 'Gdynia'. He did not expect an excessive close situation. The second officer, who relieved captain on the bridge, acquired other ship by the ARPA. He received the first calculations one minute later and was aware that the calculations could be unreliable due to the short calculation time. At the time when officer noticed that the CPA decreased to 3 cables at distance to 'Fu Shan Hai' about 3 miles, while the course and speed of 'Fu Shan Hai' were unchanged, he decided to alter the course 25 degrees to starboard in order to pass astern of her (fig. 6). After 5 minutes officer realized that there was still a risk of collision. Three minutes before collision officer started evasion maneuver setting rudder hard to starboard. However, a starboard turn at this moment was too late and the collision was imminent.

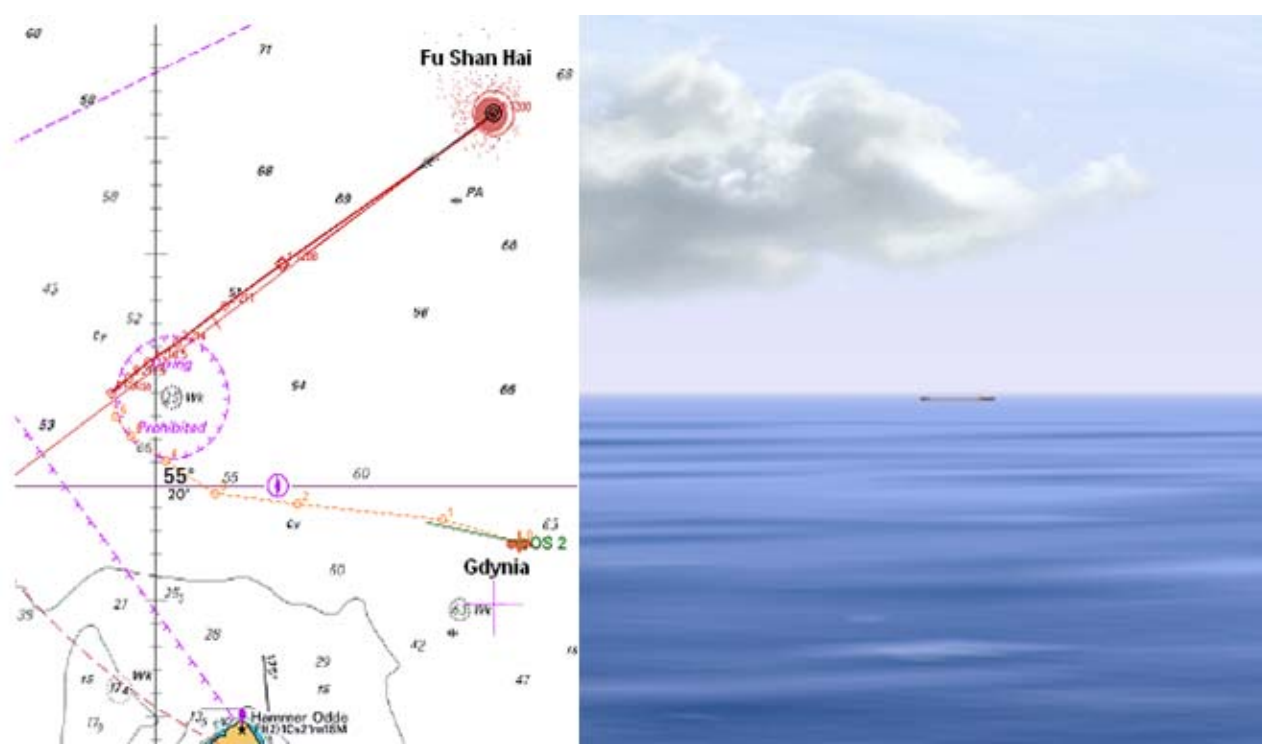

Fig. 6. Area and view of $\mathrm{m} / \mathrm{v}$ 'Fhu Shan Hai' from bridge of $\mathrm{m} / \mathrm{v}$ 'Gdynia' 15 minutes before collision [own study]

The officer of the watch focused on ARPA alone and based his judgment of the situation on its information. He could verify radar information or efficiency of maneuvers undertaken simply by visual judgment of the situation. 


\section{UNDERSTANDING DEFICIENCIES OF ONBOARD INFORMATION SYSTEMS}

The key issue of safety of navigation is not just ability to operate the ship and onboard systems. We have learned that most of the accidents which happened at sea resulting from chains of unexpected errors. One way of breaking this chain is to bring to the officer of the watch awareness of the situation and system performance. Every officer should know and understand the limitations and deficiencies of the onboard systems.

In case of the Electronic Chart and Information System (ECDIS) the computer based navigation information system offers a lot of advantages, like: displaying current situation, planning of maneuvers, displaying information from different sensors etc.

There is no doubt that ECDIS will become one of the main tools for OOW and will be main part of integrated bridge systems. Navigator could benefit from its usage and again as long as deficiencies and limitations of the ECIDS systems will be clear and understood for them. While designing of new versions of systems and training scenarios experience of those who have been using ECDIS on bard ships should be taken into account. Authors having contact with courses takers (deck officers with relevant sea experience on different ship's types and positions) found some deficiencies of usage of ECDIS in practice.

1. Users suffer of high complicated handling of equipment. For instance interface with icons, functions differs between different manufacturers.

2. Differences between systems of different producers are too big. Let us just compare two common systems Navi-Sailor 3000 ECDIS and CM-10 (fig. 7).
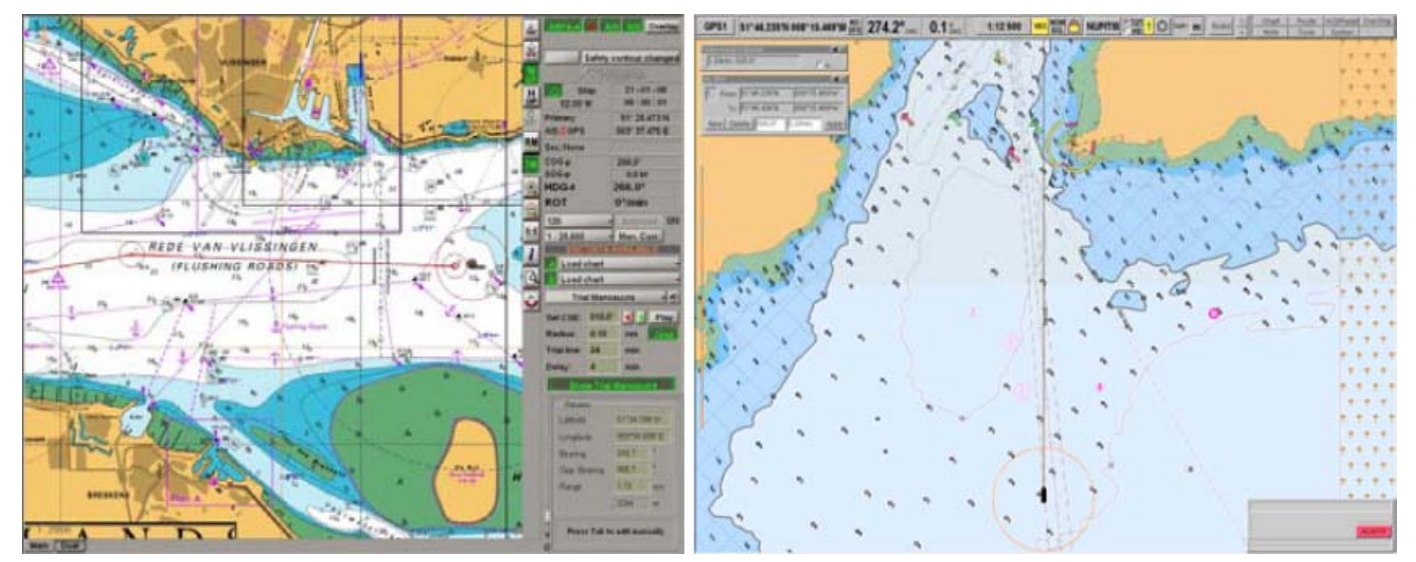

Fig. 7. Displays of Navi-Sailor and CM ECIDIS systems [own study] 
Differences are related to:

- window design,

- number and scope of options,

- accessibility of functions.

3. ECDIS may still have got number of hidden gaps (fig. 8).

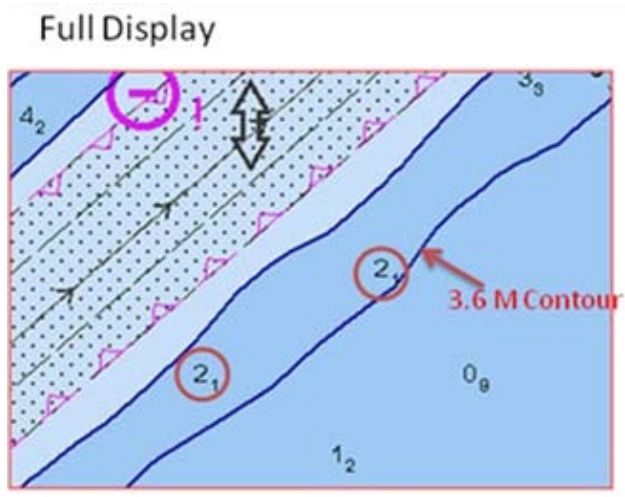

\section{Standard Display}

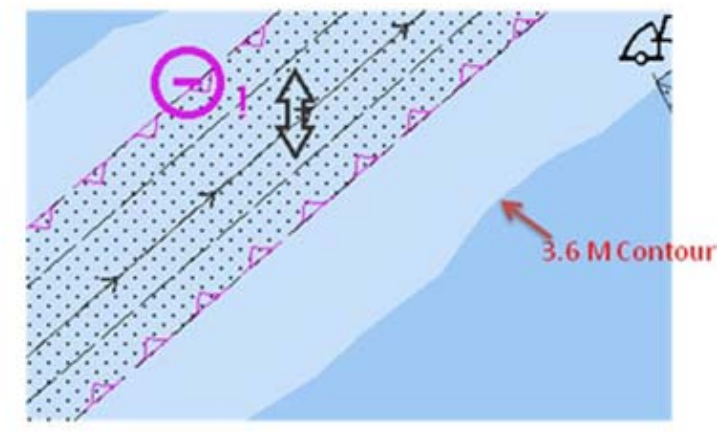

Fig. 8. Example when the operator incorrectly set parameters: safety depth and safety contour [own study]

Systems dedicated for special purpose should have similar ergonomic appearance. In practice navigator should be signed on with full knowledge and ability to use onboard equipment. Otherwise, if systems will be developed rapidly, every officer will be required to hold certificate of special training for every particular type of ECDIS.

Handling of modern navigational information systems consumes too much time. Navigators should perform proper lookout, while 'playing' with bridge systems should be limited as much as possible. In practice it commonly happens:

1. Complicated handling of systems leads to fatigue. After few hours of continuous handling users have difficulties with finding proper buttons, fields, boxes etc. They seem to be overload with number of functions, required settings, information generated by system, etc.

2. Too much information generated by systems in different display versions and modes could be tricky and in some setting those valuable information can be missed.

3. Number of alarms leads to their ignorance so that most important may be missed (Cortesia case). Navi-Sailor 3000 ECDIS-i has got 71 types of alarms. Just with sea area are associated 42. All of them cannot be switch off. Additionally there are alarms related to: AIS, monitoring of planned route, navigational obstructions, 
sensors, configuration, ARPA etc. Alarms could be generated every few minutes (table 1). They need to be assessed properly. On sea the simplest existence is the best. It could be solved by introducing so called S-mode function (safety or simple). In an areas where experience and knowledge plays main role, that mode could deliver most essential data in one commonly agreed display/format. Those areas are narrow passages, channels, fjords, junction of separation schemes, approaches, anchorages, bunker areas etc.

4. Changeable scale makes navigator not aware of real distance to obstructions. In restricted areas scale has to be changed continuously. First of all, observe the area and check the situation ahead of the ship. After few changes of scale the real distance is difficult to assess. Operators have tendency to use to big scale what could be risky in term of safety of navigation. Scale has to be always visible; additionally units should be displayed graphically. Changes would affect units what should be easy to distinguish.

Table 1. Alarm log [own study]

\begin{tabular}{|c|c|}
\hline Kind of alarm & Time \\
\hline Nav danger & $11: 09$ \\
\hline Non navigational chart & $11: 09$ \\
\hline No official chart & $11: 09$ \\
\hline Course difference & $11: 03$ \\
\hline Sounder: no input & $11: 01$ \\
\hline Sounder depth & $11: 01$ \\
\hline ARPA-B: No input & $11: 01$ \\
\hline
\end{tabular}

\section{REMARKS}

The article contains some reflection about usage of onboard information systems. Good example of such system is ECDIS which is going to be commonly used globally in shipping. Probably more and more information will be displayed on their screens from onboard and external sources and actors like:

- VTS recommendations (waypoints timing, dedicated no go areas);

- coast guard orders;

- piloting advices;

- SAR operations;

— salvage operations;

- other ship intentions; 
— dedicated tide slots;

- etc.

Discussion about model training course for ECDIS is expected to take place during the 43 STW Subcommittee sessions. Model training courses shouldn't focus on present state of art but also on the fact of rapid development of onboard information systems, especially growing functionality. It should be taken into consideration while designing the systems and training courses that:

1. Automated processes should be well understood by mariners in order to use them properly on sea.

2. If possible, systems should be as simple and user friendly as possible.

3. Systems like ECDIS or VMS could perform a lot of tasks. Number of alarms associated with those tasks and interference with alarms of another device on the bridge are too big.

4. Standardization leads to a fuller understanding of particular importance in the operation phase, but must be taken into account already in the design, configuration and installation of new systems or while modifying existing ones.

5. Increased number of hours on the simulators can improve the situation.

6. E-Learning methods can be used in the training.

7. Manufacturers my benefits from consultation with professionals (different nationalities) and there is still need for surveys to identify problems that could arise from improper or incorrect design, selection, installation and use of automated systems.

8. Attention should be paid to the ergonomics of products and their interfaces.

9. Mariners shouldn't use just one information system or same source of information.

10. Outputs of automated processes should be explained on demand [1].

\section{REFERENCES}

[1] Bak A., Chomski J., Magaj J., Pietrzykowski Z., Uriasz J., Aims and tasks of the navigational support system on a sea going Vessel, Advanced in Transport Systems Telematics, Katowice 2007.

[2] Banachowicz A., Wolejsza P., The analysis of possibilities how the collision between $\mathrm{m} / \mathrm{v}$ Gdynia and $\mathrm{m} / \mathrm{v}$ Fhu Shan Hai could have been avoided, Advances in Marine Navigation and Safety of Sea Transportation, TransNav 2007, Gdynia 2007. 
[3] BSU - Federal Bureau of Maritime Casualty Investigation: Investigation Report 01/08, Grounding of LT Cortesia on 2 January 2008 on the Varne Bank in the English Channel, Hamburg, 1 April 2009.

[4] IHO Publication S-52 Appendix 2: Addendum to Annex A, Part 1, Edition 3.4, 2008.

[5] Lloyd's Register: Sea-web data base, London 2011.

[6] MAIB - Marine Accident Investigation Branch: Report No 2/2009, Report on the investigation into the grounding of Pride of Canterbury 'The Downs' — off Deal Kent 31 January 2008, Southampton, January 2009.

[7] MSC: Circ.982, Guidelines on ergonomic criteria for bridge equipment and layout, IMO, London 2000.

[8] MSC: Circ.1061, Guidance for the operational use of integrated bridge system (IBS), IMO, London 2003.

[9] MSC: Circ.1091, Issues to be considered when introducing new technology on board ship, IMO, London 2003.

[10] MSC: Research into interaction with automated systems, MSC 82\15\2: IMO, London 2006.

[11] NAV: Report to the Maritime Safety Committee. NAV/54/2514, August 2008, IMO, London 2008.

Received May 2012

Reviewed Jun 2012 